\title{
High-energy physics needs thought
}

Proper excitement that CERN may answer many important questions should be moderated by some deliberate plan for true global collaboration in high-energy physics.

BIG-science people are a patient lot, and have to be. Projects costing $\$ 1,000$ million (such as the Hubble Space Telescope) or more (the Superconducting Super Collider, SSC, now to be built in Texas, for example) are necessarily years in gestation. Those who conceive of grand projects may often have died or retired by the time their dreams come true. The difficulties for younger people seeking to make their way in a competitive world on the basis of published contributions are even more acute. Often there may be nothing to give to prospective employers, or fellowship committees, except letters of recommendation from more senior people.

Much has been said about the sociology of these circumstances. That the originators of projects may not be those who see them through, and who reap the rewards of discovery, engenders a sense of teamwork and a seemly sense that discovery is (in Vannevar Bush's evocative phrase) an endless frontier. The minuses are different. The teams are often huge - so large that young people may be lost in them, or may find that success hangs on qualities not strictly those of science, managerial skill, for example. The other side of that coin is that young people also learn a great deal when working as members of large big-science teams.

There is also a sense in which large projects engender impatience. When people know that it will take a decade to complete a project, they are understandably eager to get on with it. But megaprojects almost always require that some government or governments should have learned to temper impatience with a proper sense of responsibility, persuading politicians that a project for which funds are sought is a significant improvement on what exists already, and is likely to yield a substantial harvest of discovery.

These platitudes are prompted by the appearance in Physical Review Letters of two articles describing the accumulated measurements at Fermilab and SLAC (the Stanford Linear Accelerator Center) of $Z^{\prime \prime}$ bosons, likely in the next few months to be produced in great abundance at CERN (the European High-Energy Physics Laboratory at Geneva). It makes sense that the data should be published now, if only as a benchmark against which CERN can calibrate its own measurements. For what it is worth, the measurements described by Fermilab and SLAC
(63, 720 and 724 respectively; 1989) agree within the experimental uncertainties both with earlier data from CERN and with the prediction of the standard theory due to Salam and Weinberg. Each article is signed by roughly 200 people; those interested may count them.

The SLAC article, interestingly, does not include the name of W.F. Panovsky, director at SLAC for many years until his retirement three years ago. That illustrates the selflessness with which the originators of important projects create them for the benefit of others: Panovsky was the driving force behind the creation at SLAC of the machine called the Stanford Linear Collider (SLC) with which SLAC's $Z^{\prime \prime}$ bosons have been made. The idea is that pulses of electrons and positrons from SLAC's main electron accelerator are separated magnetically, then focused by means of magnets in roughly semicircular arcs about a kilometre in circumference and finally made to collide.

The technique is among the most exacting so far practised even in high-energy physics. Each pulse of electrons consists of 10,000 million particles. The trick is to arrange that each pair of pulses hits the same patch of geometrical space, roughly 3 micrometres in diameter, at virtually the same time. It is understandable that it should have taken a little longer than first planned - two years extra, by some estimates - to get the counter-circulating pulses into the planned shape. No doubt everybody working on the project has learned a great deal from the experience, the virtues of patience particularly. As the only particle accelerator in which bunches of particles are fired at each other as if they were bullets, SLC will also provide useful design experience for machines not yet built. The Soviet Union has already decided in principle to build such a machine at Serpukhov, while another on the same lines is spoken of as a successor to the advanced version of the Large Electron-Positron collider now producing Z" particles at CERN.

But there is a delicate irony in all this. If SLC had indeed functioned as designed when first commissioned, it would by now have generated some thousands of unambiguously identified $Z^{\prime}$ particles and CERN would have been deprived of the opportunity to produce the definitive data on the properties of these particles, now expected in the next few months. That does not mean that the money spent on
LEP would have been wasted - there arc plenty of other things to do with LEP (sec Nature 340, 277; 1989). But the gilt would have gone from the gingerbread. And while it would be wrong to say that SLC was built to steal CERN's thunder, the sense that this might happen helped to fortify the resolve of SLAC - and helped to persuade the US Congress to approve the money.

There is also a moral. Nobody will deny that competition has a place in science. or that the competition to build more effective accelerators and to commission them on time has been an efficient spur to the development of high-energy physics. But with even (perhaps, given the federal deficit, one should say "especially") the US Congress sucking its teeth over the prospective cost of SSC, the time has come to ask what can be done to make competition more efficient, or less wasteful of resources. There is, in other words. a need that the development of new machines should be invested with a still greater sense of deliberation, however painful the present slow process of winning approval for a new project may be.

This, sadly, is where the high-energy physics communities on both sides of the Atlantic become evasive. The obvious end-point in the field is global international collaboration. So much seems generally to be accepted by high-energy physicists in the United States and Europe, but with a reservation reminiscent of that applied by St Augustine to his prayer that God should make him chaste — "but not yet". The accelerator after next is when the time will be ripe, is what the people say.

That cannot continue to be a respectable riposte. Even as things are, the reality of transatlantic collaboration in the field is substantial, as is that between Japan and European and US laboratories. Why not formalize these arrangements, which would require some kind of general consensus about the design of the next generation of accelerators and agreement about their siting? People's reservations seem usually to be stimulated by the calculation that, then, there would be only one machine being built at any time. That need not necessarily be the case, and only one machine would be better than none, the outcome if the world's taxpayers turn sour. That might mean that patience would have to be more widely practised. Would that matter?

John Maddox 